Taras Yurkiv

\title{
Continuous Improvement in Education of Chemical Engineers and Researchers in the United States
}

\author{
Taras Yurkiv \\ Retired Senior Process Engineer, BP Products North America Inc., USA \\ t yurkiv@yahoo.com
}

The education of young chemical engineers and scientists in the United States is an ongoing process of mutual improvement of universities and industry enterprises. Approaching education to business needs ensures the success of graduates and enterprises, increases the quality of education, influx of students, and the prestige of the university.

Keywords: education, training, skill, chemical, engineer, scientist, internship, co-op, bachelor, master

\section{Introduction}

The success of the professional activities of young specialists in the field of chemical engineering and science is closely linked to the level and quality of their training at universities and workplaces. Some steps and requirements for the education and training of students and young professionals in their profession and the mutual influence of professional knowledge and skills on the education process are discussed below.

\section{Education and Training of Young Chemical Engineers}

\section{Undergraduate Education}

Professional career of chemical engineers begins from earning a bachelor's degree in Chemical Engineering [1].

Some of the steps that young chemical engineers and scientist must do to earn a Bachelor's Degree Chemical Engineering, are as follows:

1. Education at Leading Universities

When hiring new college graduates, recruiters from the large oil and chemical companies are focusing their efforts at only few but top-rated educational institutions in the field of Chemical Engineering.

One of the leaders in the teaching of chemical engineering in the Midwest of the United States, the Department of Chemical and Biomolecular Engineering (CHBE) of the University of Illinois at Urbana-Champaign, for example [2], offers classes in chemical engineering that include, but are not limited to, the following:

1) Principles of Chemical Engineering

Material and Heat Balances.

2) Chemical Engineering Thermodynamics

Fundamental concepts and the laws of thermodynamics; the first and second law applications to phase equilibrium and chemical equilibrium and other applications in the Chemical Engineering profession.

3) Individual Study. 
Taras Yurkiv

Individual study of problems related to Chemical Engineering for sophomores, juniors, \& seniors.

4) Momentum \& Heat Transfer

Introduction to fluid statics and dynamics; dimensional analysis; design of flow systems; introduction to heat transfer; conduction, convection, and radiation.

5) Mass Transfer

Introduction to mass transfer processes and design methods for separation equipment.

6) Chemical Reaction Engineering

Chemical kinetics; chemical reactor design; the interrelationship between transport, thermodynamics, and chemical reaction in open and closed systems.

7) Analysis of Data

Nature of probabilistic models for observed data; discrete and continuous distribution function models; inferences on universe parameters based on sample values; control charts, acceptance sampling, and measurement theory.

8) Unit Operation Laboratory

Experiments and computation in fluid mechanics, heat transfer, mass transfer, and chemical reaction engineering.

9) Process Design

Capstone design course where students apply principles from previous courses to the design of complete chemical process systems. Topics include: techniques used in the synthesis and analysis of chemical processes, process simulation and optimization, effective communication in a chemical process engineering environment.

10) Process Control \& Dynamics

Techniques used in the analysis of process dynamics and in the design of process control systems. Laplace transforms ${ }^{1}$, stability analysis, and frequency response methods.

11) Chemical Kinetics \& Catalysis

Problems in chemical kinetics; techniques for the prediction and measurement of rates of reactions; homogeneous and heterogeneous catalysis chain reactions.

12) Projects

Laboratory; development of an individual project.

High scores in professional subjects place a student on the top of a list of job candidates.

Scores below ' $\mathrm{B}$ '2 in the above-mentioned disciplines significantly reduce the student's chances of getting a job in a large oil / chemical company.

\footnotetext{
${ }^{1}$ The purpose of the Laplace Transform is to transform ordinary differential equations (ODEs) into algebraic equations, which makes it easier to solve ODEs [3].

${ }^{2}$ The range of grades $\mathrm{A}$ (A+,A, A-) corresponds to $90-100 \%$, or 3.67-4.0 GPA (grade point average); B (B-, B, B+) corresponds to 80-89\%, or 2 .67-3.66 GPA score [4], [5]. 
Taras Yurkiv

Also important are good marks on such universal subjects as chemistry, mathematics, physics and physical chemistry.

2. Internships \& Co-ops ${ }^{3}$

While in the university, in order to graduate and gain work experience, a student must complete multiple internships \& co-ops.

In the vast majority of cases, large oil and chemical companies, while hiring young professionals, offer jobs to students before their graduation, most often, after the co-op during the final year of education.

As a rule, a student must complete at least 2-3 internships and cooperatives during his/her studies. To apply for the internship, the applicant must submit his/her Curriculum Vitae $(\mathrm{CV})^{4}$. Resumes are also acceptable.

During the internships and co-ops, a student must undergo the necessary training, complete a series of individual tasks, and demonstrate that he/she has not only the knowledge and skills necessary for the successful completion of job assignments immediately after hire, but also positive attitude towards colleagues, persistence and interest in the work he/she performs. Outstanding final presentation summarizing the work done during the internship / co-op as well as excellent characteristics of the working professionals who observe and teach students during internships/ co-op are mandatory.

The list of works of practical importance for oil refineries and chemical enterprises and laboratories, which are performed by students during internships and cooperatives, is not short. Competition in the oil and chemical industries forces oil and chemical companies to use all available resources in order to continuously improve the quality of their products, optimize chemical processes, equipment, machines, catalysts, etc., including the use of students to achieve the company's goals.

Internships and cooperatives, in turn, improve the level of on-campus education. When students who were professionally trained by industry experts return back to universities to continue their education, together with new knowledge and skills, they bring new and elevated requirements to their lecturers and instructors to the content and quality of the classes.

A student must always consider internships and co-ops as the main and in the most cases the only way to learn and improve professional skills needed to obtain an attractive job offer and succeed at work in the future.

The equally important result of internships and co-operatives is that out-of-campus education helps the student to strengthen or change (in some cases) his/her choice of future profession. The student needs to be sure that the work he/she devotes about a third of his/her

\footnotetext{
${ }^{3}$ Cooperative education programs, commonly referred to as co-ops, and internships both provide students with the opportunity to gain work experience in their career fields. Students who participate in coops stop taking classes to work full time. Co-ops are typically paid and last anywhere from three to 12 months [6].

${ }^{4}$ A curriculum vitae (CV) provides a summary of your experience and skills. Typically, CVs for entrylevel candidates are longer than resumes - at least two or three pages. The CVs include more information than resumes, particularly details related to one's academic and research background [7]
} 
Taras Yurkiv

active life is important, attractive and rewarding. When you study at a college, particularly at a junior level, it's never too late to make up your mind and change your future profession.

3. Development of Professional Skills

During the university years and early in his/her job career, a young professional must gain not only certain knowledge, but also develop and master skills needed to succeed. Some of skills listed below are mentioned in [1]:

1) Knowledge of organization's behavior, it strengths and weaknesses, risks and opportunities

2) Skills to think analytically to find potential problems and develop solutions

3) Ability to work creatively and think innovatively

4) Ability to solve problem when problem arise

5) Management skills to lead the teams of engineers and skilled workers

6) Teaching and mentoring skills

7) Ability to stay calm and work in emergencies

8) Ability to work under the constant stress

9) Ability to work in multicultural environment

10) Excellent oral and written communication skills

11) Computer skills (e.g. MS Office package, Adobe Acrobat Professional, Adobe Access, Dell Statistica, etc.)

12) Process and equipment simulation software (e.g. KBS Petro-Sim Suite, Aspen HYSYS for oil \& gas processing engineers, Aspen Plus for chemical engineers)

13) Unit health monitoring and performance analysis software \& tools (e.g. MS Visual Basic, MathWorks Matlab, PTC MathCad, MS Excel, Aspen HYSYS, KBS PetroSim Suite, OSIsoft PI ProcessBook, DataLink, etc.)

14) Foreign languages

4. Graduation with B.S. in Chemical Engineering.

Preferred scores are summa cum laude -GPA $4.0+$; magna cum laude -GPA 3.8 to 3.9; cum laude-GPA 3.5 to 3.7. Avoid GPA below 3.0.

Students who graduate from the university not only in their major in Chemical Engineering but also obtain a second (minor) degree in the related to chemical engineering practices (e.g. Material Science, Chemistry, Math, Computer Science, etc.), have a significant competitive advantage.

\section{Education and Training after Obtaining a Bachelor's Degree Professional Education and Training at Universities}

Education and training of recent graduates and working professionals continue in specialized programs at universities and in specialized professional organizations.

The Professional Master's Program (PMP) and Doctor of Philosophy (Ph.D.) Program are the most commonly forms of professional education offered by universities.

1. Professional Master's Program

${ }^{5}$ According to the USA most common higher education grading system, 'Normal courses' are graded with GPA score up to 4. 'Honor courses' are graded with a GPA score up to 5 [4], [5].

TY Continuous Impovement rev1

P a g e | 4 
Taras Yurkiv

The Professional Master's Program aims to provide advanced technical and management training to aspiring industrial leaders in chemical engineering and to prepare graduates for specialized careers in industry, academia, and government.

The Charles D. Davidson School of Chemical Engineering at Purdue University, US, for example, offers the full time, 12 - 16 month, non-thesis M.S. program to a recent graduate of a $\mathrm{STEM}^{6}$ program or a current professional [8].

During this program, students have the option to maximize their business and management component and may opt to pursue the $\mathrm{MSChE}^{7}+\mathrm{MBA}^{8}$ dual degree option.

\section{Doctor of Philosophy Program}

The Doctor of Philosophy Program is designed to prepare each student to take an active part in the development and growth of the field of chemical engineering at all levels in academia, industry, and various research organizations [9]. All admitted graduate students must demonstrate competence in graduate course work and demonstrate the capability to do independent research.

Like internships and cooperatives, recent graduates and industrial engineers' professional education improves higher education at universities. When an experienced engineers returns from industry and laboratories to universities to continue studying at M.S. or Ph.D. programs, because of the work they perform at universities (for example, by teaching some classes or helping students conducting laboratory research), they bring their professional knowledge and experiences into the learning process enhancing the content and quality of teaching.

3. Online Degrees and Certificates

Working adults, chemical engineers and scientists who want to prepare for better career opportunities, have the opportunity to learn and graduate on-line. The Department of Online Professional Certification Programs at Purdue University, for example, offers numerous graduate programs and certifications in business administration, management and leadership, project management, etc. [10].

\section{Education and Training in Professional Societies}

Less common but valuable form of continuous education for students, engineers, and scientists is education and certification in professional societies.

There are multiple professional societies in the field of chemical engineering and science in the world, e.g. European Federation of Chemical Engineering (EFCE) in Europe, American Institute of Chemical Engineers (AIChE) in North America, etc. [11].

In the professional societies, educational institutions, students and practitioners have the opportunity to receive numerous teaching materials, as well as to complete on-line and face-to-face programs and obtain certificates in the field of chemical engineering and science.

${ }^{6}$ STEM- Science, Technology, Engineering and Mathematics, is a term used to group together these academic disciplines.

${ }^{7}$ MSChE- Master of Science In Chemical Engineering

${ }^{8}$ MBA- The Master of Business Administration

TY Continuous Impovement rev1 $\quad$ P a g e | 5 
Taras Yurkiv

The Safety and Chemical Engineering Education (SAChE) program, for example, is a cooperative effort between the Center for Chemical Process Safety (CCPS) and engineering schools to provide teaching materials and programs that bring elements of process safety into the education of undergraduate and graduate students studying chemical and biochemical products and processes [12].

One of the benefits of learning in the professional societies is that students expand their knowledge in the fields that often go beyond standard university curricula.

\section{Licensed Professional Engineer}

In the USA, UK, and some other countries, licensed Professional Engineer (PE) belongs to a select group of professionals who have made the commitment to achieve excellence in their professional development by initial professional education and experience and by continuing education.

Having a PE after your name signals to employers and clients that you have competence in your field and helps set you apart from your competitors [13],[14].

In order to become a licensed PE, the engineer must hold an engineering degree from an accredited school and pass the fundamentals of engineering exam to earn a training license. After he gains four years of professional experience under the supervision of a licensed engineer, he must then pass the professional engineering exam and earn a full license. After earning the license, the engineer must maintain it by taking continuing education classes and renewing every few years [1].

Some accredited chemical engineering schools offer training programs and classes for students and working professionals to prepare them for the examination for training and professional engineer licenses.

The above path in professional education and training of engineers and scientists in the field of chemical engineering in the United States is reflected in Fig. 1.

It should be noted that such a path of education and training exists in other areas of education in the United States and beyond.

\section{Conclusions}

To increase the enrollment of students and meet the growing demand for better education and employment of its graduates, universities must approach their educational process to the business needs.

Continuous professional education and certification of chemical engineering graduates and experienced engineers and scientists at universities and beyond not only increases their employability and earning potential, but also create the conditions and provide the necessary resources to further improve the education and training of students.

Professional knowledge, experience and skills, perseverance, interest in learning and work, and a positive attitude toward colleagues are key elements that contribute to the success of the professional career of chemical engineers and scientists. 
Taras Yurkiv

\section{References}

[1] L. Thompson, "How to Become a Refinery Engineer," Chron.com. [Online]. Available: http://work.chron.com/become-refinery-engineer-30960.html. [Accessed: May 7, 2019].

[2] University of Illinois at Urbana-Champaign, Chemical and Biomolecular Engineering (CHBE), "Courses," Illiois.edu. [Online]. Available: http://catalog.illinois.edu/courses-of-instruction/chbe/. [Accessed: May 7, 2019].

[3] “What exactly is Laplace transform?" August 11, 2012. StackExchange.com. [Online]. Available: $\quad$ https://math.stackexchange.com/questions/181160/what-exactly-islaplace-transform. [Accessed: May 8, 2019].

[4] "Academic Grading in the United States," April 24, 2019. Wikipedia.org. [Online]. Available: https://en.wikipedia.org/wiki/Academic grading in the United States. [Accessed: May 7, 2019].

[5] "Honours Degree," Wikipedia.org. May 7, 2019. [Online]. Available: https://en.wikipedia.org/wiki/Honours_degree\#United_States. [Accessed: May 7, 2019].

[6] B. Boyington, "Know the Difference between a Co-Op, Internship" March 31, 2015. usnews.com. [Online]. Available: https://www.usnews.com/education/bestcolleges/articles/2015/03/31/understand-the-differences-between-a-co-op-internship [Accessed: May 7, 2019].

[7] A. Doyle, "The Difference between a Resume and a Curriculum Vitae," April 19, 2019. thebalancecareers.com. [Online]. Available: https://www.thebalancecareers.com/cv-vs-resume-2058495. [Accessed: May 7, 2019].

[8] Purdue University, Davidson School of Chemical Engineering, "Chemical Engineering Professional Master's Program," Purdue.edu. [Online]. Available: https://engineering.purdue.edu/ChE/academics/graduate/masters. [Accesses: May 9, 2019].

[9] Purdue University, Davidson School of Chemical Engineering, "Doctor of Philosophy Program," Purdue.edu. [Online]. Available: https://engineering.purdue.edu/ChE/academics/graduate/phd. [Accesses: May 9, 2019]. 
Taras Yurkiv

[10] Purdue University Global, Online Professional Certificate Programs, Purdueglobal.edu. [Online]. Available: https://www.purdueglobal.edu/degreeprograms/online-certificates/. [Accesses: May 11, 2019].

[11] "List of chemical engineering societies," Wikipedia.org. April 5, 2018. [Online]. Available: https://en.m.wikipedia.org/wiki/List of chemical engineering societies . [Accessed: May 10, 2019].

[12] SAChE - Safety and Chemical Engineering Education, Aiche.org. [Online]. Available:

https://www.aiche.org/academy/search?f $\% 5 \mathrm{~B} 0 \% 5 \mathrm{D}=\mathrm{im}$ field global content sourc e $\% 3 \mathrm{~A} 74366 \& \mathrm{f} \% 5 \mathrm{~B} 1 \% 5 \mathrm{D}=\mathrm{im}$ field_global_language $\% 3 \mathrm{~A} 73466$. [Accessed May $11,2019]$.

[13] "Should I Pursue PE Licensure?" Aiche.org. [Online]. Available: https://www.aiche.org/chenected/2017/03/should-you-pursue-pe-licensure.

[Accesses: May 11, 2019].

[14] My Skills my Future, "Certified Chemical Engineer," myskillsmyfuture.org. [Online]. Available:https://www.myskillsmyfuture.org/CertificationDetails.aspx? onetcode=17 215100\&detailonetcode $=17204100 \&$ certid $=7681 \&$ keyword $=$ Mining $\% 20 \&$ highestm atch $=$ Mining $\% 20 \&$ zipcode $=K S \&$ radius $=0 \&$ workPref $=0 \&$ ind group $=0 \&$ indsize $=0$. [Accesses: May 11, 2019]. 


\section{Taras Yurkiv}

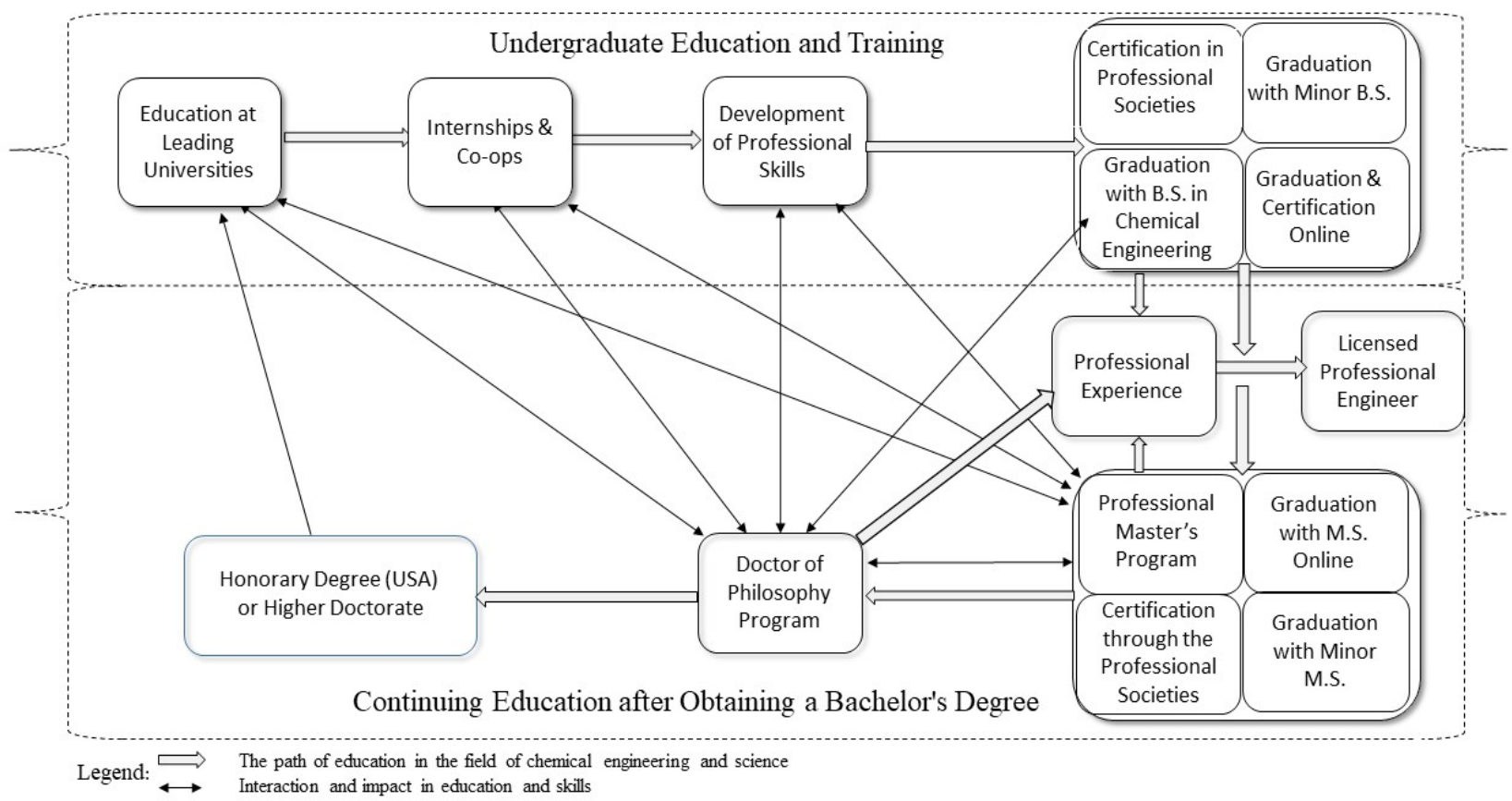

Fig. 1. Continuous improvement in education and training of chemical engineers and researchers 
Taras Yurkiv

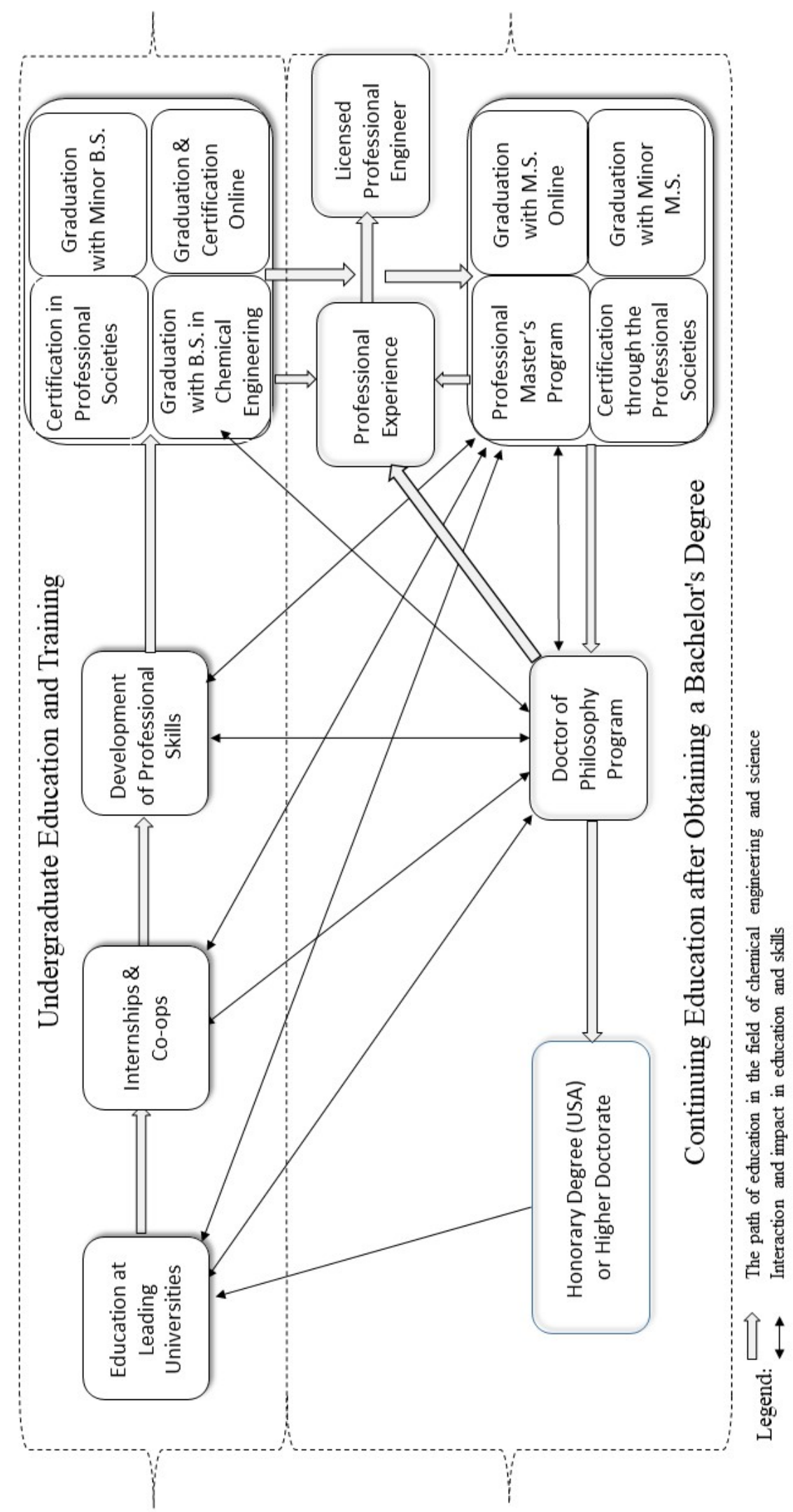

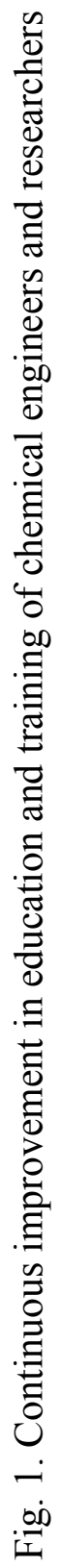

